\title{
A COMPARISON OF EPIDURAL ANALGESIA PROVIDED BY BUPIVACAINE PLUS PETHIDINE, BUPIVACAINE PLUS MORPHINE, OR BUPIVACAINE PLUS MORPHINE PLUS MIDAZOLAM FOR LOWER LIMB ORTHOPAEDIC SURGERY
}

\author{
NR Sharma ${ }^{1 *}$, U Rai ${ }^{1}$, S Panthee ${ }^{1}$, P Shrestha ${ }^{1}$ \\ ${ }^{1}$ Department of Anaesthesiology, Lumbini Medical College Palpa. \\ *Correspondence to: Dr Nil Raj Sharma, Department of Anesthesia and Critical Care, Lumbini Medical College, Pravash, Tansen, Palpa. \\ Email:nilrajnp@gmail.com
}

\begin{abstract}
Epidural anaesthesia and analgesia in orthopaedic surgeries helps to prevent thromboembolic phenomenon by increasing venodynamics. Adequate post operative analgesia with good patient satisfaction has been observed with this technique. The objective of this study was to assess the duration of postoperative analgesia and complications in patients receiving epidural anesthesia with morphine, midazolam and pethidine in combination with bupivacaine. We prospectively studied 75 Patients who were scheduled for elective lower limb orthopaedic surgery with epidural anaesthesia. This study was conducted from March 2010 to March 2012 at Lumbini Medical College Palpa. They were randomly divided by lottery method into three equal groups. Group 'A' (BP) received $50 \mathrm{mg}$ epidural pethidine $(3 \mathrm{ml})$ with $0.5 \%$ bupivacaine $13 \mathrm{ml}$. Group 'B' (BM) received $5 \mathrm{mg}(3 \mathrm{ml})$ epidural morphine with $13 \mathrm{ml}$ of $0.5 \%$ bupivacaine and Group' C' (BMM) received $5 \mathrm{mg}(1 \mathrm{ml})$ epidural morphine with $13 \mathrm{ml} 0.5 \%$ bupivacaine and $2 \mathrm{mg}(2 \mathrm{ml})$ epidural midazolam. All the patients were observed for 24 hours for quality of analgesia and other side effects like nausea vomiting, and pruritus. Data were analysed by SPSS-16.0 software. The result of the study shows the duration of analgesia was prolonged in BMM group than BM, and BP group and was statistically significant ( $\mathrm{P}$ value $<0.001$ ). Incidence of nausea and vomiting in BMM group was lower than that of BP and BM group but was statistically insignificantly (P value 0.489 ). Pruritus was absent in BP group and was more with $\mathrm{BM}$ and BMM group (P value 0.007). In conclusion the use of epidural morphine and midazolam in combination with bupivacaine is the satisfactory method of post operative analgesia. By adding midazolam, duration of analgesia can be increased with decrease in incidence of nausea, vomiting and pruritus.
\end{abstract}

Key Words: Epidural analgesia, Midazolam, Morphine, Pethidine.

\section{INTRODUCTION}

Perioperative pain is a potent trigger for the stress response. Thus, the effective analgesia may improve patient outcome. ${ }^{1}$ Epidural morphine provides more complete analgesia than other route of administration. ${ }^{2}$ Studies show that the use of epidural opioids or combinations of epidural opioids and local anaesthetics may improve outcome and decrease hospitalisation time. ${ }^{3}$ Epidural anaesthesia provides not only good post operative analgesia but also has good venodynamic effects so to prevent intra operative as well as post operative thromboembolic phenomena. ${ }^{4,5}$ When midazolam is added, it acts through GABA receptors and enhances the affinity of GABA receptors. ${ }^{6}$ Studies had revealed that use of epidural midazolam has been reported to be an effective analgesic in adult. ${ }^{7}$

\section{METHODS}

We prospectively studied 75 Patients who were scheduled for elective lower limb orthopaedic surgery with epidural anaesthesia to determine post operative analgesia and side effects. This study was conducted from 2010 March to 2012 March in Lumbini Medical College Palpa. They were randomly divided by lottery method into three equal groups. Group 'A' (BP) received 50 $\mathrm{mg}$ epidural Pethidine $(3 \mathrm{ml})$ with $0.5 \%$ Bupivacaine $13 \mathrm{ml}$. Group ' $\mathrm{B}$ ' $(\mathrm{BM})$ received $5 \mathrm{mg}(3 \mathrm{ml})$ epidural Morphine with $13 \mathrm{ml}$ of $0.5 \%$ Bupivacaine and Group ' $\mathrm{C}$ ' $(\mathrm{BMM})$ received

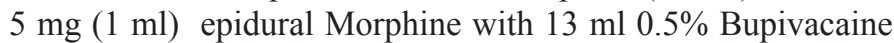
and $2 \mathrm{mg}(2 \mathrm{ml})$ epidural Midazolam Informed consent was taken from all patients. Inclusion criteria included patients undergoing Orthopaedic surgery of lower extremities scheduled for elective surgery with epidural anaesthesia and analgesia. Exclusion criteria included patients taking tranquilizers, history of substance abuse, allergy to morphine, pethidine, midazolam, cardiac compromised, respiratory compromised and coagulation abnormalities. All patients received an infusion of $1.0-1.5 \mathrm{~L}$ of Ringer's lactate solution intravenously prior giving epidural anaesthesia. The epidural catheter was inserted at the L4 - L5 interspace. When surgery lasted more than two hours, $10 \mathrm{ml}$ of $0.5 \%$ Bupivacaine was given and repeated every 2 hourly. Postoperatively all three groups received $8 \mathrm{ml}$ of $0.1 \%$ Pethidine and $0.1 \%$. Bupvacaine upon first complain of pain. Afterwards it was given every two hourly or as per patients' demand for 
next 72 hours. The incidence of nausea, vomiting and pruritus during the study period were recorded by the ward nurse for 24 hours. In addition, the respiratory rate was measured every four hour. The use of Promethazeine, for the treatment of nausea and vomiting and Pheniramine maleate, for pruritus was also recorded. If pruritus is severe, naloxne was administered. The patients completed a questionnaire at the end of the study period detailing whether they would have adequate postoperative pain control and side effects related to epidural medicines. Data were analysed by SPSS version 16 for windows.

\section{RESULTS}

There were a total of 75 patients included in the study as shown in table 1 . Out of them $48(64 \%)$ were male and the rest $27(36 \%)$ were female. Mean age of the total patients was $49.8 \pm 39.4$. Each group i.e., BP, BM and BMM had 25 patients. The mean age of the patients in each group was as shown in table 2. The duration of analgesia was prolonged in BMM group than BM, and BP group. It was statistically significant ( $\mathrm{P}$ value $<0.001)$ as shown in table 3. Incidence of nausea and vomiting in BMM group was lower than that in other two groups though it was not statistically significant ( $P$ value 0.489 ) as shown in table 4 . Pruritus was absent in BP group and was significantly more with $\mathrm{BM}$ and BMM group (P value 0.007) as shown in table 5.

Table 1 : Age and sex composition

\begin{tabular}{|l|c|c|c|c|c|}
\hline Age (years) & Male & Female & Total & Mean Age & S.D \\
\hline $16-25 y r s$ & 10 & 3 & 13 & 20.53 & 3.01 \\
\hline $26-35 y r s$ & 6 & 2 & 8 & 30.25 & 2.65 \\
\hline $36-45 y r s$ & 8 & 1 & 9 & 40.33 & 2.87 \\
\hline $46-55 y r s$ & 6 & 7 & 13 & 50.38 & 2.36 \\
\hline $56-65 y r s$ & 5 & 7 & 12 & 61.41 & 2.53 \\
\hline $66-75 y r s$ & 9 & 2 & 11 & 69.36 & 1.36 \\
\hline $76-85 y r s$ & 4 & 5 & 9 & 78.66 & 2.00 \\
\hline Total & 48 & 27 & 75 & & \\
\hline
\end{tabular}

Table 2: Mean age in each group

\begin{tabular}{|l|l|l|l|}
\hline & BP(group A) & BM(group B) & BMM(group C) \\
\hline $\mathrm{N}$ & 25 & 25 & 25 \\
\hline $\begin{array}{l}\text { Mean age } \\
\text { (years) }\end{array}$ & 50.7600 & 45.0000 & 53.6400 \\
\hline $\begin{array}{l}\text { Std. } \\
\text { Deviation }\end{array}$ & 20.83523 & 17.87922 & 20.08706 \\
\hline
\end{tabular}

\begin{tabular}{|c|c|c|c|c|}
\hline \multirow[t]{2}{*}{ Medicine } & \multicolumn{4}{|c|}{ Analgesia duration in hours } \\
\hline & $<8 \mathrm{hr}$ & $8-16 \mathrm{hr}$ & $>16 \mathrm{hr}$ & \multirow{5}{*}{$\mathrm{P}<0.001$} \\
\hline $\begin{array}{l}\text { BP } \\
\text { (group A) }\end{array}$ & $25(100 \%)$ & 0 & 0 & \\
\hline $\begin{array}{l}\text { BM } \\
\text { (group B) }\end{array}$ & 0 & $16(64 \%)$ & $9(36 \%)$ & \\
\hline $\begin{array}{l}\text { BMM } \\
\text { (group C) }\end{array}$ & 0 & $6(24 \%)$ & $19(76 \%)$ & \\
\hline Total & $\begin{array}{c}25 \\
(33.33 \%)\end{array}$ & $\begin{array}{c}22 \\
(29.33 \%)\end{array}$ & $28(37.33)$ & \\
\hline
\end{tabular}

Table 4: Incidence of nausea and vomiting in different study groups

\begin{tabular}{|c|c|c|c|}
\hline Medicine & \multicolumn{3}{|c|}{ Nausea and vomiting } \\
\hline & Present & Absent & \multirow{5}{*}{$\mathrm{P}=0.489$} \\
\hline BP (group A) & $\mathrm{n}=11(44 \%)$ & $\mathrm{n}=14(56 \%)$ & \\
\hline BM (group B) & $\mathrm{n}=12(48 \%)$ & $\mathrm{n}=13(52 \%)$ & \\
\hline BMM (group C) & $\mathrm{n}=8(32 \%)$ & $\mathrm{n}=17(68 \%)$ & \\
\hline Total & $\mathrm{n}=31(41.33 \%)$ & $\mathrm{n}=44(58.66 \%)$ & \\
\hline
\end{tabular}

Table 5: Incidence of pruritus in different study groups

\begin{tabular}{|l|l|l|l|}
\hline Medicine & \multicolumn{2}{|l|}{ Pruritus } & \\
\hline & Present & Absent & \\
\cline { 1 - 2 } BP (group A) & 0 & $\mathrm{n}=25(100 \%)$ & \\
\cline { 1 - 2 } BM (group B) & $\mathrm{n}=7(28 \%)$ & $\mathrm{n}=18(72 \%)$ & \multirow{2}{*}{$\mathrm{P}=0.007$} \\
\cline { 1 - 2 } BMM (group C) & $\mathrm{n}=2(8 \%)$ & $\mathrm{n}=23(92 \%)$ & \\
\hline Total & $\mathrm{n}=9(12 \%)$ & $\mathrm{n}=66(88 \%)$ & \\
\hline
\end{tabular}

\section{DISCUSSION}

Surgical stress consistently elicits a metabolic response by activation of the sympathetic and somatic nervous system and through local trauma. ${ }^{8}$ Responses to surgical stress include release of neuroendocrine hormones and local release of cytokines. Serum concentrations of these factors correlate with severity of injury. Thus, the concept has arisen that inhibiting the stress response may improve surgical outcome. ${ }^{9}$ The result in our study shows that epidural midazolam is more reliable and satisfactory for post operative pain management when used in combination with morphine and bupivacaine in adults. Although the extensive preclinical testing may see burdensome, the risk-benefit relationship for epidural midazolam justifies the 
need. There is convincing evidence that epidural midazolam is superior for post operative pain management in combination with morphine. Our study reveals that the use of midazolam in combination with morphine and bupivacaine has reduced the incidence of morphine induced side effects like nausea, vomiting but statistically it is not significant $(\mathrm{P}=0.489)$. There is decrease incidence of pruritus with prolongation of analgesia duration with use of midazolam which is highly significant with non midazolam group ( $\mathrm{p}$ value $0.007,<0.001$ respectively). The addition of midazolam has significantly increased the analgesia duration than morphine alone. When morphine was used in combination with bupivacine, $36 \%$ patients had more than 16 hours of analgesia duration. It was increased to $76 \%$ with addition of midazolam with same dose of bupivacaine and morphine which was strongly significant with types of medicine and duration of analgesia ( $p$ value $<0.001$ ). Elhakim $M$ et al have proved that addition of midazolam in combination with morphine not only prolongs the duration of analgesia but also has good antiemetic effect. In our study also the incidence of pruritus was remarkably decreased by addition of midazolam. The incidence of pruritus was decreased from 28\% (in BM) group to $8 \%$ (in BMM group). Other similar studies also have revealed that the incidence of morphine induced side effects like nausea, vomiting and pruritus are reduced with the use of midazolam. ${ }^{11}$ The most troublesome side effect of epidurall morphine is nausea and vomiting and pruritus. Some of the studies have revealed that the incidence of nausea and vomiting is upto $30 \%$ following epidural and intrathecal morphine. ${ }^{12}$ Our study reveals that nausea and vomiting was higher in BM and BP group (48\%,44\% respectively). In these group four patients $(16 \%)$ in BM group and two patients in BP group had single dose of promethazeine to control nausea and vomiting. No patient needed naloxone in both the group. It is been observed that with addition of midazolam in BMM group the incidence of nausea and vomiting was decreased to (32\%) however statistically it is not significant $(\mathrm{P}=0.489)$. The underlying mechanism of nausea and vomiting following epidural opioid is not related to systemic absorption of drug. The incidence may or may not be related to the dose of opioid administered and may be higher when epidural morphine is utilized. ${ }^{13}$ Sensitization of the vestibular system to motion and decreased gastric emptying produced by opioids may also play a role in nausea and vomiting induced by intrathecal and epidural opioids. ${ }^{14}$

Another common side effect of intrathecal and epidural opioids is pruritus. It may be generalized but is more likely to be localized to the face, neck, or upper thorax. It is higher in epidural or intrathecal route than others. The incidence varies widely; from 0 to 100 percent. ${ }^{15}$ Pruritus induced by intrathecal and epidural opioids is likely due to cephalad migration of the drug in cerebrospinal fluid and subsequent interaction with the trigeminal nucleus located superficially in the medulla. ${ }^{6}$ Our study reveals that pruritus was $28 \%$ with BM group and two patients $(8 \%)$ had single dose of injection pheniramine maleate. There was no use of naloxone in any patients. When midazolam is added with morphine (in BMM) group) the incidence was reduced to $8 \%$. Thus the addition of midazolam in combination with morphine and bupivacaine during epidural analgesia and anaesthesia is satisfactory method of controlling post operative pain and side effects related to morphine.

\section{CONCLUSION}

Combined use of epidural midazolam with morphine and bupivacaine can reduce the incidence of morphine induced side effects as well as potentiates the analgesic effects of morphine and bupivacaine.

\section{REFERENCES}

1. Kehlet H. Surgical stress: The role of pain and analgesia. $\mathrm{Br}$ J Anaesth 1989;63:189-195.

2. Harrison DM, Sinatra R, Morgese L. Epidural narcotics and PCA for postcesarean section pain relief. Anesthesiology 1988; 68:454-457.

3. Yeager MO, Glass DD, Neff RD, Brinck-Johnsen T. Epidural anesthesia and analgesia in high-risk surgical patients. Anesthesiology 1987;66:729-736.

4. Christopherson R, Beattie C, Frank SM, Norris EJ, Meinert CL, Gottlieb SO, Yates H, Rock P, Parker SD, Perler BA, Williams M. Perioperative morbidity in patients randomized to epidural or general anesthesia for lower-extremity vascular surgery. Anesthesiology 1993;79:422-434.

5. Tuman KJ, McCarthy RJ, March RJ, DeLaria GA, Patel RV, Ivankovich AD. Effects of epidural anesthesia and analgesia on coagulation and outcome after major vascular surgery. Anesth Analg 1991;73:696-704.

6. Edward M, Serrao JM, Gent JP. The mechanism by which midazolam causes spinally mediated analgesia .Anesthesiology 1990;73:273-277.

7. Yama T, Hanaoka K. Effect of diluent volume on postoperative analgesia and sedation produced by epidurally administered midazolam. Eur J Anaesthesiol 1998;15:275.

8. Weissman C. The metabolic response to stress: An overview and update. Anaesthesiology 1990;73:308-327.

9. Kehlet H. The stress response to surgery: Release mechanisms and the modifying effect of pain relief. Acta Chirurgica Scand 1988;550:22-28.

10. Elhakim M, Abd-Elfattah H, El-Din DN, El-Kabarity R, Atef A, El-Fakey A. Midazolam as an antiemetic in patients receiving epidural morphine for postoperative pain relief. J Opioid Manag 2009;5(4):189-95.

11. Ballantyne JC, Loach AB, Carr DB. Itching after epidural and spinal opiates. Pain 1988;33:149-60.

12. Cousins MJ, Mather LE. Intrathecal and epidural administration of opioids. Anesthesiology 1984;61:276-310.

13. Nordberg G, Hedner T, Mellstrand T, Dahlström B. Pharmacokinetic aspects of intrathecal morphine analgesia. Anesthesiology 1984;60:448-54.

14. Morgan M. The rational use of intrathecal and extradural opioids. Br J Anaesth 1989;63:165-88.

15. Gustafsson LL, Schildt B, Jacobsen K. Adverse effects of extradural and intrathecal opiates: report of a nationwide survey in Sweden. Br J Anaesth 1982;54:479-86. 